\title{
A Semi-portable Enclosure to Measure Emission Rates from Small Fugitive Sources: Leaf Blower Dust Example
}

\author{
Dennis Fitz", David Pankratz, Sally Pederson, James Bristow \\ College of Engineering-Center for Environmental Research and Technology, University of \\ California, Riverside, Riverside, CA 92507, USA
}

\begin{abstract}
Small fugitive particulate matter (PM) sources may make significant impacts to urban air pollution. The PM emission rates for most of these have not been measured due to the difficulty involved. The EPA addresses some fugitive emission rates in their AP-42 document and these generally were developed from upwind-downwind sampling. A semi-portable enclosure was designed and evaluated for determining PM emission rates from landscape cleaning operations such as leaf blowing, raking, and sweeping. The method consisted of an enclosure to confine PM emissions while performing these activities on actual in-use surfaces while making measurements using realtime PM analyzers. In this enclosure the cleaning equipment could be operated in the same way as normally done. To evaluate the enclosure's mixing and exchange rates, propene gas was released and used as a tracer. PM emission rates were then calculated from measured concentrations, the dimensions of the enclosure, and area over which the cleaning operation was performed. To evaluate this method, cleaning operations were performed after the pavement floor was vacuumed and then spiked with surrogate debris. To make actual emission rate measurements, the enclosure was placed over landscape with debris from normal grounds maintenance activities. Emission rates were determined as a function of surface type and cleaning tool used. The method would be appropriate for many types of small fugitive dust sources.
\end{abstract}

\section{OPEN ACCESS}

Keywords: Particulate matter, Test enclosure, Fugitive dust, $\mathrm{PM}_{10}$

Received: February 22, 2021

Revised: June 18, 2021

Accepted: July 5, 2021

${ }^{*}$ Corresponding Author:

dfitz@cert.ucr.edu

\section{Publisher:}

Taiwan Association for Aerosol Research

ISSN: $1680-8584$ print

ISSN: 2071-1409 online

(c) Copyright: The Author(s). This is an open access article distributed under the terms of the Creative Commons Attribution License (CC BY 4.0), which permits unrestricted use, distribution, and reproduction in any medium, provided the original author and source are cited.

\section{INTRODUCTION}

In epidemiological studies particulate matter (PM) has been shown to cause a wide variety of adverse health effects and to contribute to premature deaths (Pope et al., 1995; Layden et al. 2006). In order to mitigate the effects of this pollutant, the sources of the PM should be known as well as possible so that effective control methods may be applied. Receptor modeling by Chow et al. (1992) has shown that $\mathrm{PM}_{10}$ of geologic origin is often a significant contributor to the PM concentrations in urban areas that are not in PM attainment.

Landscape cleaning operations often appear to be obvious sources of particulate emissions and quite likely include geologic dust. To compile emission inventories, many agencies use the AP-42 document compiled by the U.S. Environmental Protection Agency (U.S. EPA) to estimate PM emission rates from various processes (U.S. EPA, 1995). While this document has a section on fugitive dust emission rate measurements and default values, it focused on industrial emissions, not small consumer sources. For example, in order to estimate PM emission rates from leaf blowers, the California Air Resources Board (2000) used estimates based on engineering principles and assumptions in addition to silt loadings measured in the gutters of paved roadways. These estimations of emission rates have not been validated and therefore have unknown accuracy.

The objective of this study was to develop a method to measure PM emission rates from small fugitive dust generating activities. These emission rates combined with activity data could then 
be used to determine the significance of such activities and the need for mitigation. Landscape cleaning operations such as leaf blowers and their alternatives were chosen to measure their $\mathrm{PM}_{10}$ emission rates using actual surfaces on which they are most commonly performed. While fugitive emission sources are generally quantified using upwind-downwind measurements coupled with either flux measurements or modeling (dispersion and/or receptor), this was impractical for landscape cleaning operations since a single cleaning operation would significantly and irreversibly alter the characteristics of the surface to be cleaned.

\section{METHODS}

The approach used in measuring the PM emissions from landscape cleaning operations was based on having the tool clean a defined area in an enclosed space to confine the emissions and monitoring the PM concentrations in real-time until they stabilized. This would indicate that the PM inside the enclosure was well mixed, and concentrations at this point could be used to calculate the emission rate before more particles settled out. To determine the extent of mixing and the air exchange rate, propene tracer gas was injected into the enclosure just prior to the cleaning operation and the concentrations were then measured in real-time during the cleaning operation and mixing periods. The details of this approach can be found in the final report (Fitz, 2006). Some of the results were also presented at a U.S. PEA conference (Fitz et al., 2006) in a presentation that focused on a $20 \mathrm{~m}$ long chamber, which was used initially to evaluate the approach, but was too unwieldly to move from location to location.

In order to evaluate the enclosure method on different surfaces, a surrogate mixture of soil and vegetative debris was developed that would be representative of those surfaces in actual use. With this consistent medium, various cleaning devices could be compared and the measurement variability determined. Emission measurements were then made in situ on actual landscape next to maintenance operations.

The enclosure had to be large enough to operate the devices and long enough to generate consistent emissions while being of a manageable size and weight so that two people could move it to various locations. A ten meter long enclosure was constructed that was two meters high and wide. The frame for the enclosure was constructed of 1-inch $(2.5 \mathrm{~cm})$ PVC pipe using aluminum slip-on framing fittings. The frame was then covered with polyethylene sheeting which was held to the ground with sand bags. Fig. 1 shows the enclosure and frame supporting the polyethylene sheeting.

Thermo Systems Inc. (Shoreview, MN) Model 8520 DustTrak $^{\mathrm{TM}}$ aerosol monitors placed directly in the enclosure were used to measure total suspended particulate matter (TSP), $\mathrm{PM}_{10}$, and $\mathrm{PM}_{2.5}$ in real-time. The size cuts were made by impactors that came with the instruments. PM concentrations were determined by measuring the intensity of light from a diode laser that is scattered by $90^{\circ}$. The DustTraks were calibrated at the factory using Arizona road dust (NIST SRM 8632). Since the response of these analyzers depends on the size-distribution and optical properties of the particulate matter, collocated filter samplers were used during each test to

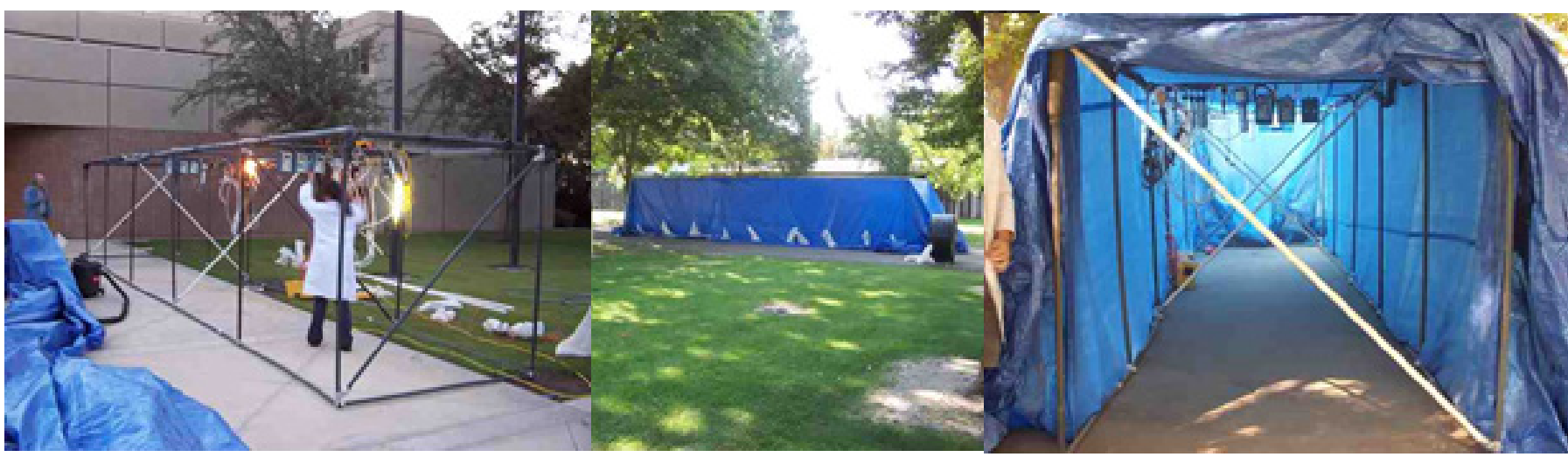

Fig. 1. Photographs of the enclosure and frame. 
verify the mass-accuracy for the aerosol being measured. For all measurements the instruments' time constant was set at one second, which is the fastest available rate. The response to zero air was checked daily by placing a filter on the inlet. Data were collected using instruments' internal storage.

Filter samples were collected on $47 \mathrm{~mm}$ Pall (Port Washington, NY) Teflo ${ }^{\mathrm{TM}}$ filters with a $2.0 \mu \mathrm{m}$ pore size. Graseby-Andersen model 246B Federal Reference Method inlets placed directly in the enclosure were used to collect filter samples with a $\mathrm{PM}_{10}$ size-cut. These inlets were modified to allow a Savillex (Eden Prairie, MN) PFA Teflon open-face filter assembly to be directly attached to the inlet. These filter samplers operated at $16.7 \mathrm{~L} \mathrm{~min}^{-1}$. A Sensidyne (St. Petersburg, FL) model 240 cyclone also placed directly in the enclosure and sampling at approximately $110 \mathrm{~L} \mathrm{~min}^{-1}$ was used to provide the $\mathrm{PM}_{2.5}$ cut-point. The outlet of the cyclone was directly attached to a closedface Savillex filter assembly. Prior to weighing, filters were equilibrated at $23^{\circ} \mathrm{C}$ and $40 \%$ relative humidity for at least 24 hours prior. Filter were weighed before and after sampling to the nearest $\mu \mathrm{g}$ with a Cahn Model 34 microbalance.

For each test propene gas was introduced into the enclosure to determine the mixing and exchange rates. A polyethylene bag was filled with $3 \mathrm{~L}$ of pure propene gas and then released in several seconds over the entire length of the enclosure. The propene concentrations were measured using a RAE Systems (San Jose, CA) ppbRAE photoionization hydrocarbon analyzer using a 10.3 electron-volt detector. The lower detection limit for propene is approximately $50 \mathrm{ppb}$. The calculated propene concentration was approximately $75 \mathrm{ppm}$ after mixing, well above this detection limit. The concentration data as a function of time was obtained with 5 -sec resolution from the instrument's internal data logger. The instrument was placed $2 \mathrm{~m}$ in at a height of $2 \mathrm{~m}$.

The hand-held electric leaf blower was a Black \& Decker (Towson, MD) Model BV 4000. A rake and push broom were procured from a home supply store for examining alternate methods to leaf blowers.

Collected debris was sorted into six size fractions using a W.S. Tyler Co. (Mentor, OH) Ro-Tap model RX-29 sieve shaker. The five sieves used were No. 3/8 $(9500 \mu \mathrm{m})$, No. $4(4750 \mu \mathrm{m})$, No 18 $(1000 \mu \mathrm{m})$, No. $40(425 \mu \mathrm{m})$ and No. $200(75 \mu \mathrm{m})$. Soil used to make the surrogate debris was made by sieving local soil and using the soil that passed through the No. 40 sieve.

\section{RESULTS}

Emission factors for fugitive sources are generally determined by performing upwind/downwind measurement studies and using either flux measurements or modeling to calculate emission rates. The flux measurement method was used to determine many of the fugitive dust emission factors presented in the U.S. EPA AP-42 document (Cowherd et al., 1974). These included paved and unpaved roads, construction activities, and surface mining sources. This approach is useful for continuous or semi-continuous fugitive emissions that allows enough time to collect measureable and representative data. For activities such as using a leaf blower to clean a surface, there is insufficient time to collect a representative sample and the activity cannot be repeated since the surface is now "clean". Another approach has been to perform the activity in a tunnel in which the emissions can be briefly confined so that more robust measurements can be made. This was reported by Fitz and Bumiller (2000) to determine the PM emission rates from street sweepers. While this approach was practical and useful for comparing various models of sweepers, there was significant uncertainty in the determination of representative concentrations and air velocity. The approach presented here was to confine the activity to an enclosure of known size and wait until the PM concentrations were generally uniform.

\subsection{Method Validation}

In order to evaluate the enclosure method to determine leaf blower emissions, it was necessary replicate tests as precisely as possible. A surrogate representative sample of debris was needed. Following landscaping staff at University of California campuses, 32 locations were selected from areas that were about to be cleaned by leaf blowers or sweeping. One-meter square areas were vacuumed and the collected material was separated into six size ranges using sieves. 
Table 1 shows the mass found in each of the six size fractions along with the composite mass for each of the samples collected. The total mass ranged from 2 to 377 grams. Some vegetative material was found in the finer sieve fractions and some soil in the larger sieve fractions. Based on these results, a surrogate material was chosen that consisted of $120 \mathrm{~g}$ of soil (mass after passing through a No. 40 sieve), $60 \mathrm{~g}$ of leaves and $60 \mathrm{~g}$ of grass clippings. This surrogate mixture was spread evenly over a $5 \mathrm{~m}^{2}$ area in the $10 \mathrm{~m}$ long enclosure as shown in Fig. 2.

Since eight DustTraks would be used to characterize the PM concentrations in the enclosure, it was necessary to compare them collocated using surrogate material dispersed by a leaf blower in the enclosure. Correction factors were then calculated to normalize the responses of the DustTraks to a single reference instrument. Separate tests were performed using the TSP, PM10 and $\mathrm{PM}_{2.5}$ inlets. Fig. 3 shows a concentration time series for three separate test runs for the eight collocated DustTraks using the TSP inlet. The DustTraks were mounted at a height of $2 \mathrm{~m}$ and $6 \mathrm{~m}$ from the start point of the leaf blower at one end of the $10 \mathrm{~m}$ enclosure. Approximately five minutes were required for the concentrations to stabilize. The mean TSP concentrations for the eight samplers were calculated between minutes five and ten, ten and fifteen and fifteen and twenty. For each time interval, the values of each of seven DustTraks were divided by the value of the one selected as a reference. The inverse of this ratio was then used to normalize the values of each DustTrak to the reference. Table 2 shows these normalization factors obtained for the three particle cut-points for all of the DustTraks.

The homogeneity of the PM concentrations in the enclosure as a function of time was evaluated in order to measure the amount of PM generated by the cleaning device used. The goal was to

Table 1. Fractionation of debris collected immediately before actual leaf blowing/operations.

\begin{tabular}{|c|c|c|c|c|c|c|c|}
\hline Sample Description & $\begin{array}{l}\text { Total } \\
\text { Mass } \\
\text { (grams) }\end{array}$ & $\begin{array}{l}>3 / 8 \\
\text { fraction } \\
\text { (grams) }\end{array}$ & $\begin{array}{l}<3 / 8 \\
>\# 4 \\
\text { fraction } \\
\text { (grams) }\end{array}$ & $\begin{array}{l}<\# 4, \\
>\# 18 \\
\text { fraction } \\
\text { (grams) }\end{array}$ & $\begin{array}{l}<\# 18, \\
>\# 40 \\
\text { fraction } \\
\text { (grams) }\end{array}$ & $\begin{array}{l}<\# 40, \\
>\# 200 \\
\text { fraction } \\
\text { (grams) }\end{array}$ & $\begin{array}{l}<\# 200 \\
\text { fraction } \\
\text { (grams) }\end{array}$ \\
\hline Asphalt Driveway - General cleaning & 377.3 & 2.8 & 24.8 & 136.5 & 74.2 & 104.8 & 34.3 \\
\hline Concrete Walkway - Lawn trimmings & 49.5 & 0.9 & 0.5 & 8.3 & 32.3 & 4.8 & 2.7 \\
\hline Textured Concrete Walkway - Lawn trimmings & 10.4 & 0.4 & 1.1 & 5.0 & 2.5 & 1.1 & 0.2 \\
\hline Concrete Walkway - General cleaning & 36.1 & 9.9 & 8.8 & 14.6 & 1.9 & 0.8 & 0.1 \\
\hline Brinks - General cleaning & 55.2 & 11.5 & 19.6 & 12.3 & 5.4 & 4.9 & 1.5 \\
\hline Concrete Walkway - General cleaning & 24.2 & 11.9 & 7.3 & 1.5 & 1.1 & 1.7 & 0.8 \\
\hline Concrete Walkway - General cleaning & 10.5 & 0.5 & 0.5 & 4.4 & 1.3 & 2.5 & 1.4 \\
\hline Concrete Steps - General cleaning & 16.2 & 6.9 & 2.9 & 3.6 & 1.5 & 1.2 & 0.2 \\
\hline Concrete Walkway - General cleaning & 4.6 & 1.0 & 0.7 & 0.5 & 0.4 & 1.4 & 0.6 \\
\hline Concrete Walkway - Lawn trimmings & 14.6 & 2.8 & 1.2 & 6.4 & 3.2 & 1.1 & 0.0 \\
\hline Concrete Walkway - Lawn trimmings & 36.6 & 12.1 & 5.9 & 13.0 & 4.0 & 1.5 & 0.1 \\
\hline Asphalt Parking Lot - Lawn trimmings & 26.2 & 1.9 & 3.6 & 17.3 & 3.1 & 0.2 & 0.0 \\
\hline Concrete Walkway - Lawn trimmings & 2.3 & 0.0 & 0.2 & 0.9 & 0.8 & 0.3 & 0.1 \\
\hline Concrete Walkway - General cleaning & 22.6 & 4.3 & 6.2 & 8.8 & 2.3 & 0.7 & 0.2 \\
\hline Asphalt Parking Lot - General cleaning & 75.2 & 9.4 & 11.2 & 13.5 & 12.1 & 20.8 & 8.2 \\
\hline Lawn - Leaves and debris & 109.7 & 0.0 & 4.3 & 34.9 & 37.1 & 26.1 & 7.2 \\
\hline Gutter - Debris & 30.9 & 0.3 & 2.1 & 9.6 & 7.9 & 7.5 & 3.5 \\
\hline Concrete Walkway - Lawn trimmings & 2.8 & 0.0 & 0.0 & 0.4 & 0.5 & 1.8 & 0.2 \\
\hline Gutter - Debris & 96.8 & 0.1 & 3.2 & 19.8 & 29.6 & 42.1 & 2.0 \\
\hline Lawn - Leaves and debris & 5.0 & 0.0 & 0.0 & 1.1 & 2.3 & 1.6 & 0.1 \\
\hline Asphalt Driveway - General cleaning & 12.2 & 0.0 & 0.7 & 3.4 & 2.7 & 4.3 & 1.1 \\
\hline Packed Dirt and Gravel Parking - General cleaning & 50.0 & 21.6 & 6.5 & 8.0 & 5.4 & 6.3 & 2.3 \\
\hline Lawn - Leaves and debris & 35.0 & 9.1 & 4.1 & 7.7 & 4.2 & 9.1 & 0.8 \\
\hline Average & 48 & 5 & 5 & 14 & 10 & 11 & 3 \\
\hline Minimum & 2 & 0 & 0 & 0 & 0 & 0 & 0 \\
\hline Maximum & 377 & 22 & 25 & 136 & 74 & 105 & 34 \\
\hline Median & 26 & 2 & 3 & 8 & 3 & 2 & 1 \\
\hline Standard Deviation & 77 & 6 & 6 & 28 & 17 & 23 & 7 \\
\hline
\end{tabular}




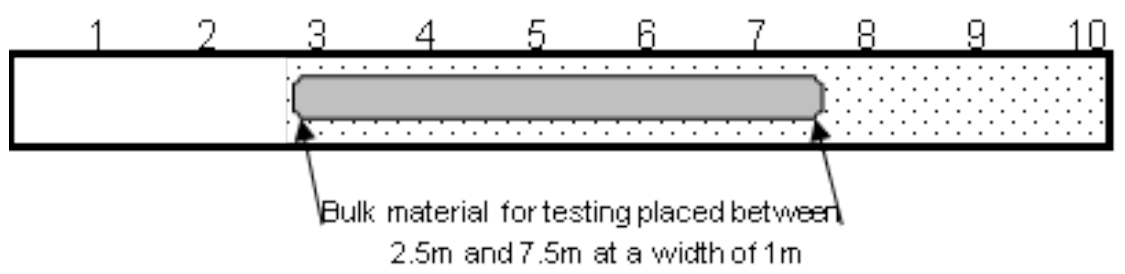

Fig. 2. Top view of test enclosure showing test material distribution.

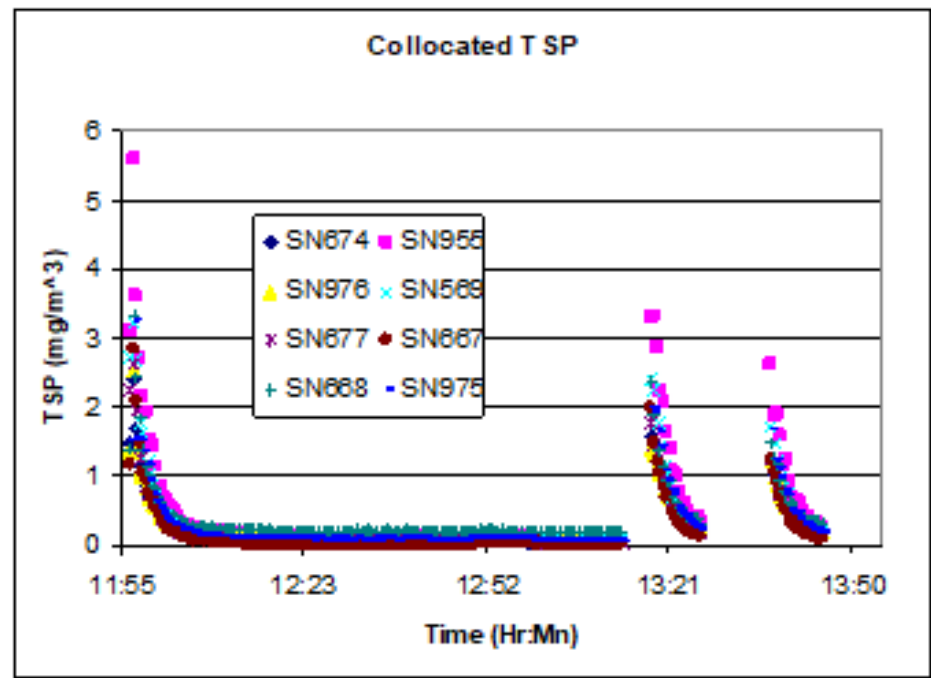

Fig. 3. TSP time-series plots for eight DustTraks collocated in $10 \mathrm{~m}$ enclosure.

Table 2. Collocated DustTrak ${ }^{\mathrm{TM}}$ mean response ratios.

\begin{tabular}{lllllllll}
\hline Size & 677 & 955 & 674 & 667 & 975 & 976 & 668 & 569 \\
\hline 2.5 & 1 & 1.00 & 0.84 & 1.24 & 0.94 & 1.00 & 1.00 & 1.01 \\
10 & 1 & 0.68 & 0.71 & 0.83 & 0.62 & 0.75 & 0.81 & 0.96 \\
TSP & 1 & 0.76 & 0.93 & 1.03 & 0.85 & 1.14 & 0.87 & 0.71 \\
\hline
\end{tabular}

determine at what time the PM became adequately mixed to minimize the losses incurred due to particle settling. Pairs of DustTraks were placed at horizontal distances of 2, 4, 6 and $8 \mathrm{~m}$ from the enclosure entrance (where cleaning operations were started). One from each pair was placed at a height of $1 \mathrm{~m}$ and the second was placed at a height of $2 \mathrm{~m}$. With this configuration both the vertical and horizontal concentration gradients could be determined at the same time. Testing of the $10 \mathrm{~m}$ enclosure was performed on a concrete surface using surrogate material deposited as shown in Fig. 2 and the electric leaf blower. Separate tests were performed with the DustTraks equipped with TSP, $\mathrm{PM}_{10}$ and $\mathrm{PM}_{2.5}$ inlets. The results from these tests were used to determine the placement of PM samplers in performing subsequent emission rate measurements using "as found" debris.

Fig. 4 shows a time series for a homogeneity test with the DustTraks using the $\mathrm{PM}_{10}$ inlets. The concentrations were initially high and variable during the leaf blowing operation, especially for the locations further from the start of blowing location. During the leaf blowing operation, the high and variable concentrations are likely due to short-lived plumes of dust around each instrument. After completion of leaf blowing, the PM concentrations at all locations began to reach a more common value. Between three to six minutes after the end of the leaf blowing, the PM concentrations became nearly similar. After six minutes, concentrations continued to decrease at a near constant rate for the following twenty minutes. The tracer gas concentrations generally showed this mixing trend, although the gas is expected to mix more rapidly due to the dispersal method and not settling out, as the particles would. After being well-mixed, the tracer gas concentrations decreased 


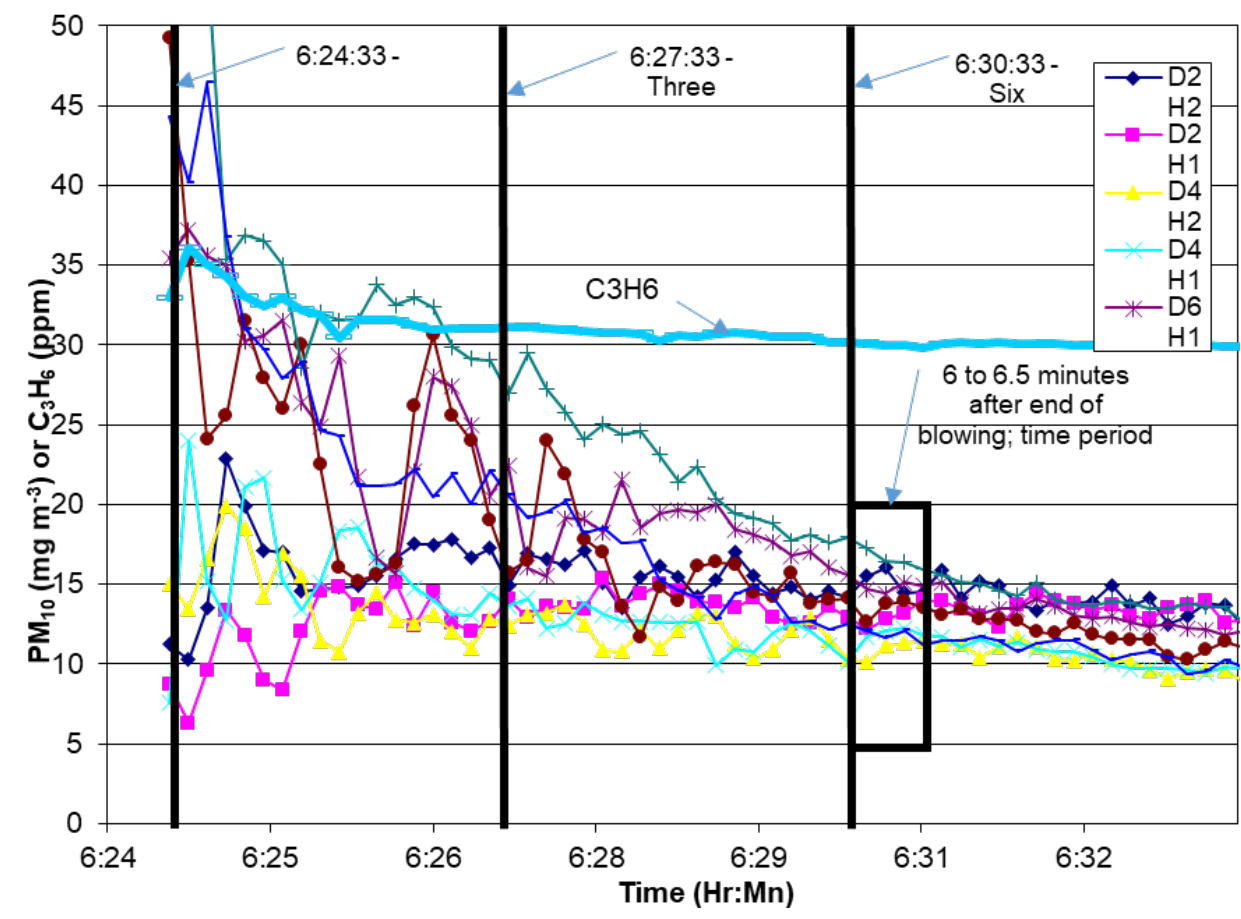

Fig. 4. Time series of DustTrak ${ }^{\mathrm{TM}} \mathrm{PM}_{10}$ responses for horizontal and vertical distribution characterization. In the key the $D$ value is the distance from the end of the enclosure where blowing is initiated in meters, and the $\mathrm{H}$ value is the height, in meters.

at a rate of approximately one percent per minute, indicating that the enclosure was slowly exchanging ambient air.

Table 3 presents the results from subsequent test runs for TSP, $\mathrm{PM}_{10}$ and $\mathrm{PM}_{2.5}$ averaging the concentration data between 6.0 and 6.5 minutes after completing the blowing operation. Although there was some variability between which DustTrak ${ }^{\mathrm{TM}}$ was highest or lowest for a specific run, indicating incomplete and inconsistent mixing, these data indicate that there was sufficient mixing and repeatability within our experimental error.

Since the vertical concentration differences were approximately the same as the measurement uncertainty, for subsequent tests the DustTraks were all placed at a height of $2 \mathrm{~m}$. Using the data in Table 3 shows that if only two locations were used, ( $2 \mathrm{~m}$ high, $2 \mathrm{~m}$ in and $2 \mathrm{~m}$ high and $6 \mathrm{~m}$ in) the results would differ from the overall mean by $18 \%$ for $\mathrm{PM}_{2.5}, 0 \%$ for $\mathrm{PM}_{10}$, and $12 \%$ for TSP.

Sets of three DustTraks (one each of TSP, $\mathrm{PM}_{10}$ and $\mathrm{PM}_{2.5}$ ) were then placed at two and six meters in from the start of cleaning operations. Two additional DustTraks $\left(\mathrm{PM}_{10}\right.$ and $\left.\mathrm{PM}_{2.5}\right)$ were placed at six meters in to collect collocated samples for calculating measurement precision. At a height of $2 \mathrm{~m}$, the relative standard deviation for all horizontal distances was $15 \%$ for $\mathrm{PM}_{2.5}, 21 \%$

Table 3. Concentration data $\left(\mathrm{mg} \mathrm{m}^{-3}\right)$ from tests to determine concentration gradients in the enclosure.

\begin{tabular}{|c|c|c|c|c|c|c|c|c|c|}
\hline \multirow{2}{*}{ Run } & \multirow{2}{*}{ Size } & \multicolumn{2}{|c|}{ Distance $2 \mathrm{M}$} & \multicolumn{2}{|c|}{ Distance $4 \mathrm{M}$} & \multicolumn{2}{|c|}{ Distance $6 \mathrm{M}$} & \multicolumn{2}{|c|}{ Distance $8 \mathrm{M}$} \\
\hline & & Height $1 \mathrm{M}$ & Height $2 \mathrm{M}$ & Height $1 \mathrm{M}$ & Height $2 \mathrm{M}$ & Height $1 \mathrm{M}$ & Height $2 \mathrm{M}$ & Height $1 \mathrm{M}$ & Height $2 \mathrm{M}$ \\
\hline 0906_1 & $\mathrm{PM}_{10}$ & 12.7 & 15.3 & 11.3 & 10.5 & 14.9 & 13.5 & 17.2 & 12.1 \\
\hline 0906_2 & $\mathrm{PM}_{10}$ & 12.0 & 11.2 & 11.7 & 11.7 & 14.1 & 13.4 & 15.6 & 12.3 \\
\hline 0906_3 & $\mathrm{PM}_{10}$ & 6.1 & 7.1 & 7.7 & 7.6 & 9.3 & 9.7 & 12.8 & 11.5 \\
\hline 0906_4 & $\mathrm{PM}_{2.5}$ & 2.3 & 1.7 & 2.4 & 1.3 & 1.8 & 1.3 & 1.8 & 1.4 \\
\hline 0906_5 & $\mathrm{PM}_{2.5}$ & 1.7 & 1.9 & 2.8 & 1.4 & 2.1 & 1.6 & 2.5 & 1.2 \\
\hline 0906_6 & $\mathrm{PM}_{2.5}$ & 2.0 & 1.9 & 2.6 & 1.5 & 3.0 & 1.8 & 2.9 & 1.5 \\
\hline 0906_7 & TSP & 5.9 & 6.7 & 5.5 & 7.5 & 9.5 & 8.2 & 11.4 & 6.0 \\
\hline 0906_8 & TSP & 5.9 & 5.7 & 5.8 & 4.5 & 7.6 & 4.7 & 12.5 & 4.0 \\
\hline 0906_9 & TSP & 9.3 & 6.6 & 10.8 & 4.4 & 14.4 & 4.8 & 11.7 & 4.2 \\
\hline
\end{tabular}


for $\mathrm{PM}_{10}$ and $25 \%$ for TSP. This is the order of values expected assuming that smaller particles are more homogeneous due to their lower settling velocity.

\subsection{Measurement Tests Performed on "as Found" Areas}

The enclosure method was used to measure leaf blower PM emissions from "as found" areas that were tested as landscape maintenance staff were ready to use a leaf blower. These areas included a lawn-concrete interface, a curb gutter, a lawn, and packed soil. Fig. 5 shows the cleaning patterns used for these areas. For the lawn-concrete interface, the enclosure was placed $0.3 \mathrm{~m}$ onto a recently mowed lawn with remaining $1.7 \mathrm{~m}$ covering the adjoining concrete surface. Starting $1 \mathrm{~m}$ in, the leaf blower was directed to blow material directly back on to the lawn to the end of the enclosure. For the gutter, the enclosure was set up in a similar manner with $0.3 \mathrm{~m}$ covering the sidewalk. In this case material was either raked or blown from $1 \mathrm{~m}$ in straight to the end of the enclosure. To test only lawn orpacked soil surfaces, the enclosure was placed to fully cover these surfaces and raked or blown from $1 \mathrm{~m}$ in straight to the end of the enclosure.

The emission rate were calculated using the following equation:

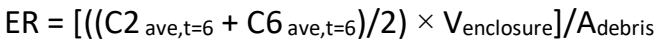

The ER $\left(\mathrm{mg} \mathrm{m}^{-2}\right)$ is the emission rate, $\mathrm{C} 2$ and $\mathrm{C} 6$ are the concentrations $\left(\mathrm{mg} \mathrm{m}^{-3}\right)$ determined at 2 and $6 \mathrm{~m}$ in, respectively, from the end where cleaning operations were started averaged over the interval between 6 and 6.5 minutes after cleanup started, $V$ is the volume of the enclosure $\left(\mathrm{m}^{3}\right)$ and $A$ is the area $\left(\mathrm{m}^{-2}\right)$ over which the debris was spread.

Table 4 lists the emission rates measured varying the surface type and the cleaning tool. The emission rates varied over a much broader range than the measurement variability of $15-25 \%$ observed during the characterization of the enclosure using surrogate debris. Power blowing of grass on concrete was the most comparable to power blowing of the surrogate soil on concrete performed during the enclosure evaluation and the emission rates were similar but varied widely. Using the results from collocated DustTrak ${ }^{\mathrm{TM}}$ analyzers, the precision for the $\mathrm{PM}_{2.5}$ measurement was calculated to be $19 \%$ and that for $\mathrm{PM}_{10} 27 \%$. These values are similar to the variability between test runs using surrogate debris.
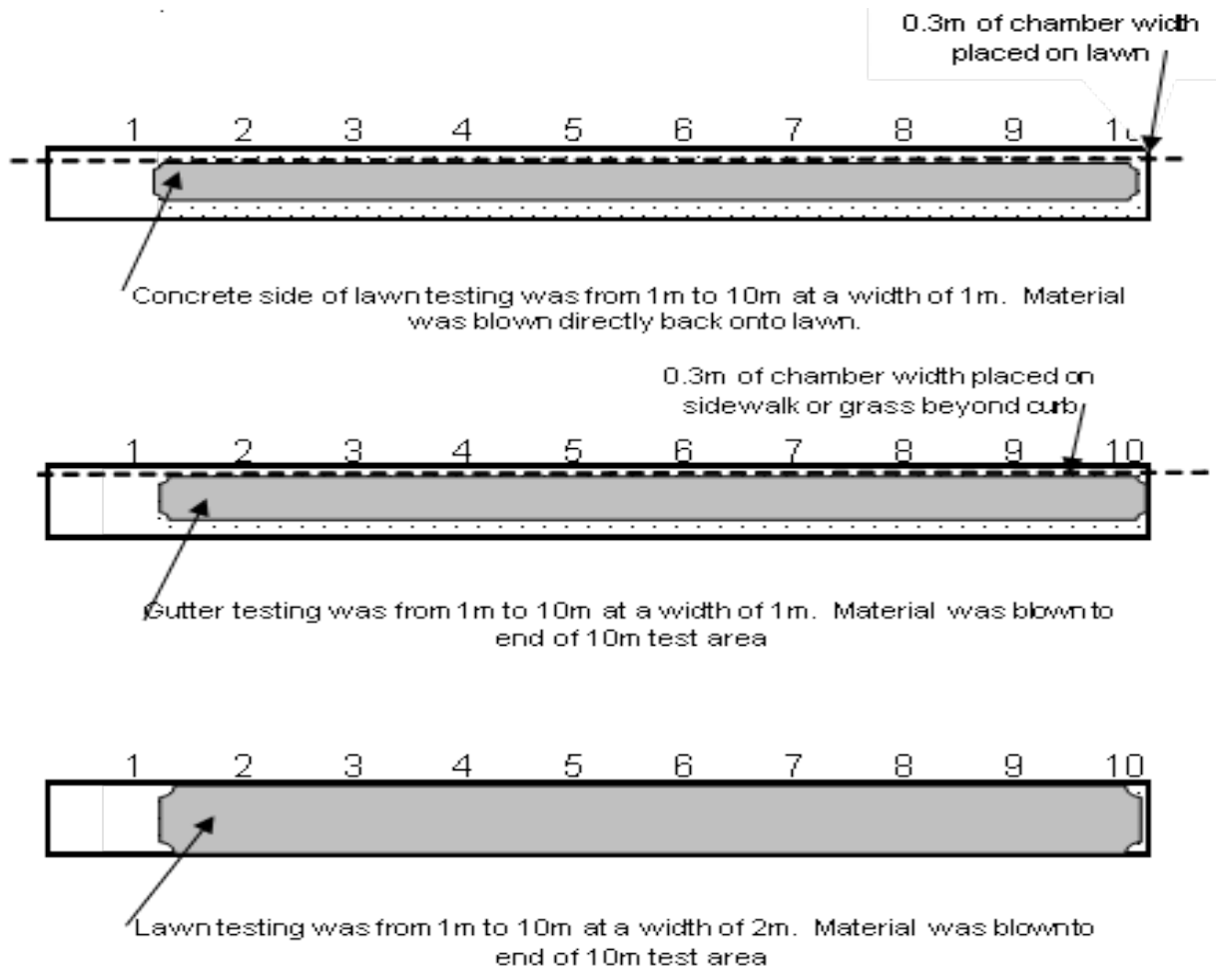

Fig. 5. Placement of the enclosure on various surfaces readies for leaf blowing operations. 
Table 4. Emission rates for leaf blowing "as found" surfaces.

\begin{tabular}{|c|c|c|c|c|c|c|}
\hline Surface Cleaned/Location & Cleaning Tool & $\begin{array}{l}\text { Area Cleaned } \\
\left(\mathrm{m}^{-2}\right)\end{array}$ & $\begin{array}{l}\text { Cleaning Time } \\
\text { (mm:ss) }\end{array}$ & $\begin{array}{l}\mathrm{PM}_{2.5} \\
\left(\mathrm{mg} \mathrm{m}^{-2}\right)\end{array}$ & $\begin{array}{l}\mathrm{PM}_{10} \\
\left(\mathrm{mg} \mathrm{m}^{-2}\right)\end{array}$ & $\begin{array}{l}\text { TSP } \\
\left(\mathrm{mg} \mathrm{m}^{-2}\right)\end{array}$ \\
\hline Lawn - Riverside & Elec. Leaf Blower & 18 & 01:46 & 0.2 & 0.5 & 0.5 \\
\hline Lawn - Riverside & Elec. Leaf Blower & 18 & 01:15 & 0.2 & 0.3 & 0.5 \\
\hline Lawn - Kearney & Elec. Leaf Blower & 18 & $00: 44$ & 0.1 & 0.2 & 0.3 \\
\hline Lawn - Kearney & Elec. Leaf Blower & 18 & $00: 20$ & 1.5 & 5 & 9 \\
\hline Asphalt Driveway - Riverside & Elec. Leaf Blower & 10 & 01:43 & 3.8 & 14 & 15 \\
\hline Asphalt Driveway - Riverside & Elec. Leaf Blower & 10 & 02:11 & 3.1 & 10 & 10 \\
\hline Asphalt Driveway - Kearney & Elec. Leaf Blower & 18 & $00: 49$ & 2.6 & 11 & 20 \\
\hline Asphalt Driveway - Kearney & Elec. Leaf Blower & 18 & $00: 20$ & 34 & 67 & 93 \\
\hline Gutter - Riverside & Elec. Leaf Blower & 5.4 & $00: 57$ & 1.5 & 5 & 7 \\
\hline Gutter - Kearney & Elec. Leaf Blower & 9 & $00: 58$ & 17 & 50 & 106 \\
\hline Gutter - Kearney & Elec. Leaf Blower & 9 & $00: 50$ & 7 & 21 & 25 \\
\hline Grass on Concrete Walkway - Kearney & Elec. Leaf Blower & 9 & $00: 46$ & 2.3 & 9 & 16 \\
\hline Grass on Concrete Walkway - Kearney & Elec. Leaf Blower & 9 & $00: 58$ & 0.3 & 1.3 & 2.4 \\
\hline Packed Dirt Parking Lot - Kearney & Elec. Leaf Blower & 18 & $00: 35$ & 71 & 118 & 163 \\
\hline Gutter - Kearney & Rake & 9 & $01: 28$ & 0.4 & 2.2 & 3.2 \\
\hline Gutter - Kearney & Rake & 9 & 01:31 & 0.7 & 3.1 & 3.9 \\
\hline Lawn - Kearney & Rake & 18 & $02: 20$ & 0.3 & 0.8 & 1.3 \\
\hline Grass on Concrete Sidewalk - Kearney & Push Broom & 9 & 01:36 & 2 & 8 & 10 \\
\hline Asphalt Driveway - Kearney & Push Broom & 18 & 03:11 & 9 & 35 & 39 \\
\hline
\end{tabular}

Several conclusions can be drawn from Table 4:

- Using a leaf blower on a gutter or grass on a concrete walkway resulted in emission rates similar to using this device on the surrogate debris.

- Using a leaf blower on packed soil resulted in the highest emission rates

- Using a leaf blower on grass did not create significant emissions

- Sweeping with a broom on concrete created significant PM emissions rates whereas sweeping asphalt resulted in much lower emission rates.

- Raking leaves did not generate significant amounts of PM.

The DustTrak ${ }^{\mathrm{TM}}$ monitor measurement is based on light scattering of particles. The amount of scattering is dependent on the particle size-distribution and the optical properties of the particulate matter. The instruments are calibrated at the factory using a suspension of Arizona road dust. Air quality regulations are often based on mass measurement methods. The relationship between the DustTrak ${ }^{\mathrm{TM}}$ measurement and the mass-based one was derived by comparing the DustTrak ${ }^{\mathrm{TM}}$ average signal integrated over the filter sampling time with the filter-based mass concentration measurement. Since $\mathrm{PM}_{10}$ is generally the primary regulatory concern for fugitive dust, this comparison was made for the 'as found" measurements as shown by the plot in Fig. 6 . The $\mathrm{R}^{2}$ value is 0.99 and the slope is 1.46 , indicating that the DustTrak ${ }^{\mathrm{TM}}$ value is significantly lower than that of the filter-based measurement for these types of particles.

\section{DISCUSSION AND CONCLUSIONS}

Measurements of fugitive dust emission rates are usually determined from upwind-downwind sampling by either calculating the PM flux through a horizontal plane using a high density of vertical and horizontal measurements or using a dispersion model with inputs from a smaller number of measurements. The flux method was used in determining the fugitive PM emission factors in AP-42 (U.S. EPA, 1995). This is described in detail by Cowherd et al. (1974). While this method is useful for continuous or semi-continuous sources, it would not be practical for cleaning operations such as leaf blowing. It would be very difficult to characterize a plume from these oneshot emission sources, since once it was conducted, the surface being cleaned would be irreversibly changed. It would be difficult to characterize the emission rate from a single plume of dust that disperses in a few seconds using a practical number of measurement instruments. 


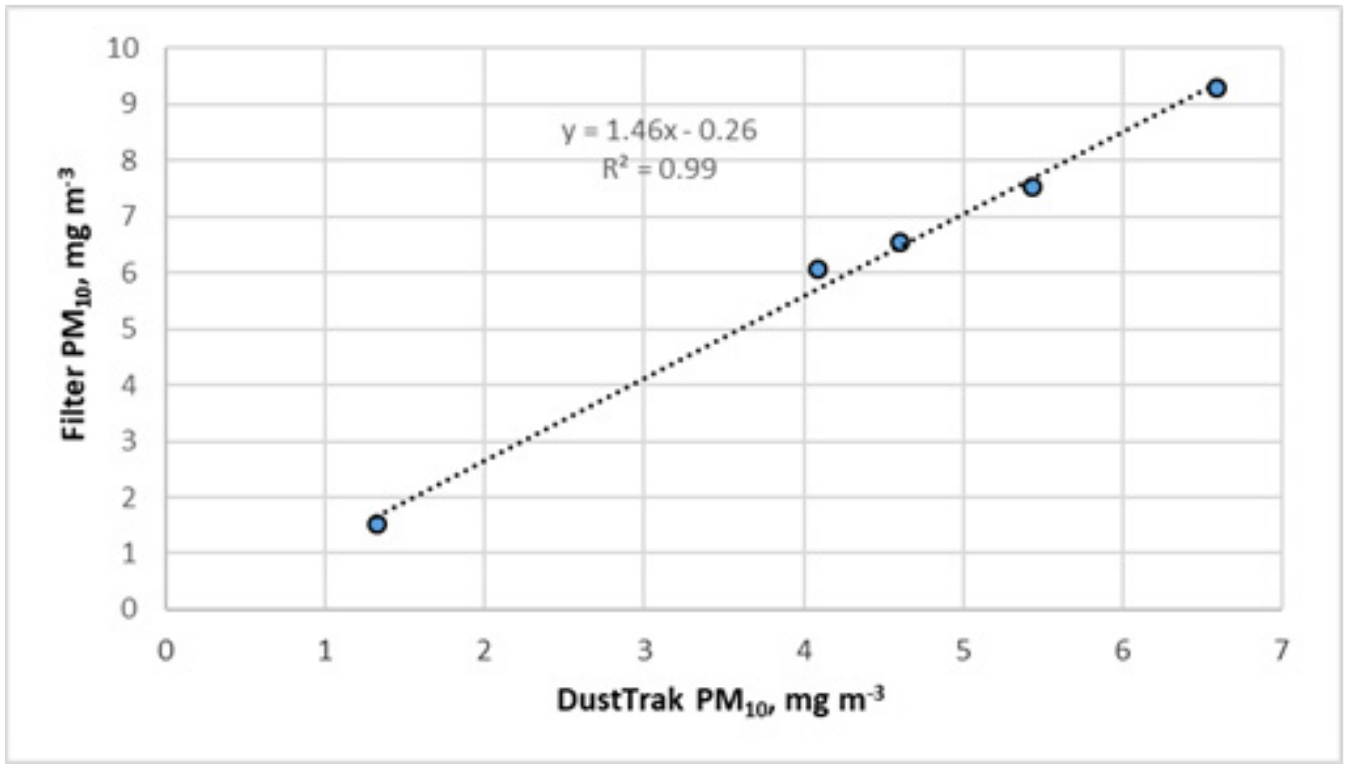

Fig. 6. Comparison of $\mathrm{PM}_{10}$ of collocated DustTrak ${ }^{\mathrm{TM}}$ and filter sampler.

More recent approaches to measuring fugitive dust emissions use optical remote sensing to characterize the plume concentrations. Hashmonay et al. (2009) used laser transmissometry combined with a vertical array of dust monitors used to calibrate the laser data. Another approach Holman et al. (2001) used lidar combine with a vertical array of PM sensors. These optical techniques are more useful for large emission areas due to the long path length on which they are operated on. Enclosures have been shown to be more useful for small one-time emission sources. Roney and White (2006) used a wind tunnel to measure emissions from soil surfaces. Scaling up a wind tunnel to the size required to operate a leaf blower would not be practical due to the cost and difficulty in moving from site-to-site. Lundgren (1986) used an enclosure to characterize the emissions from handling granular mining products. This was the approach that was used in the results presented here.

A semi-portable enclosure was used to measure fugitive PM emission rates from small fugitive sources such as paved surface cleaning operations. The approach was to use an enclosure $(2 \mathrm{~m}$ wide, $2 \mathrm{~m}$ high and $10 \mathrm{~m}$ long) in which cleaning devices such as leaf blowers, rakes, and brooms could be operated as normally conducted while confining PM emissions for concentration measurement by real-time sensors. The enclosure used a lightweight PVC pipe frame covered with polyethylene sheeting that could be moved from one location to another. To calculate the amount of PM generated in $\mathrm{mg} \mathrm{m}^{-2}$, the concentration in $\mathrm{mg} \mathrm{m}^{-3}$ (once it stabilized) is multiplied by the volume of the enclosure $\left(\mathrm{m}^{3}\right)$ and then divided by the area treated in $\mathrm{m}^{2}$.

Surrogate debris was used on an asphalt surface within the enclosure to characterize the PM variability within the enclosure, estimate the time needed for the PM concentrations to stabilize, and determine the optimum placement of the analyzer inlets. Two sample points at $2 \mathrm{~m}$ above the surface and 2 and $6 \mathrm{~m}$ along the length of the enclosure were found to be appropriate. The PM concentrations were found to be adequately stabilized after 6 minutes and concentrations were averaged between 6 and 6.5 minutes to determine the PM emission rate. Propene gas was injected prior to cleaning operations to measure the exchange rate, which was approximately $1 \%$ per minute, indicating little leakage from the enclosure. The reproducibility was found to be from 15 to $25 \%$ depending on the PM size range.

The $\mathrm{PM}_{10}$ concentrations were stable in the test enclosure for at least 20 minutes showing that the $\mathrm{PM}_{10}$ does not settle out rapidly and would stay in suspension long enough to contribute to the general $\mathrm{PM}_{10}$ loading in the area. Since many urban areas are not in compliance with $\mathrm{PM}_{10}$ standards based on adverse health effects, any additional increase in concentration would be detrimental to the health of the area's population.

The test system was then transported to areas that were about to have grounds maintenance personnel use leaf blowers for cleaning the surface. We report here for the first time the PM emission 
rates from surface cleaning operations using leaf blowers, rakes, and brooms on "as found" surfaces. The highest emission rate was from packed soil, while the lowest was on grass. While raking leaves resulted in low PM emission rates, using a broom resulted in higher emission rates, especially on a concrete surface. In the latter case the PM emission rates were comparable to those from a leaf blower and similar to those observed when using surrogate debris.

While using a leaf blower on asphalt driveways and street gutters is a much different process than street sweeping blowsand on asphalt as reported by Fitz and Bumiller (2000), it is interesting to compare their emission rates. The former resulted in a mean of $25 \mathrm{mg} \mathrm{m}^{-2}$ while the latter had a mean of $40 \mathrm{mg} \mathrm{m}^{-3}$. While there was significant variability in both and too few samples to statistically treat, the emissions of these processes were qualitatively similar.

This general enclosure approach would be useful in determining emission rates for many small operations that produce fugitive emissions, whether it is a particulate or gaseous pollutant. For operations that don't include pollutants from disturbing the soil, it would be prudent to evaluate the chamber for the time needed to achieve homogeneity.

\section{ACKNOWLEDGEMENTS}

The financial support from the San Joaquin Valley Unified Air Pollution Control District is gratefully appreciated along with the helpful assistance of Gary Arcemont from the District.

We wish to thank the following organizations and individuals for their time and resources in contributing to the success of the measurement program:

- The UC Kearney Research and Extension Center for allowing the use of their site in the San Joaquin Valley.

- The UCR Physical Plant Building Services and Grounds Maintenance for coordinating with us for the collection of samples from areas about to be leaf blown.

- The UCR Environmental Health and Safety Department for reviewing our planned activities, identifying and supplying the appropriate personal protective gear.

- Professors Mark Matsumoto and Marko Princevac at UCR and Professor Arthur Winer at UCLA for supplying measurement equipment.

\section{DISCLAIMER}

The statement and conclusions in the Report are those of the contractor and not necessarily those of the San Joaquin Valley Unified Air Pollution Control District. The mention of commercial products, their source, or their use in connection with material reported herein is not to be construed as actual or implied endorsement of such products.

\section{REFERENCES}

California Air Resources Board (2000). A Report to the California Legislature on the Potential Health and Environmental Impacts of Leaf Blowers. California Environmental Protection Agency, California.

Chow, J.C., Watson, J.G., Lowenthal, D.H., Solomon, P.A., Magliano, K., Ziman, S., Richards, L.W. (1992). PM10 source apportionment in California's San Joaquin valley. Atmos. Environ. 26, 3335-3354. https://doi.org/10.1016/0960-1686(92)90350-T

Cowherd, C., Jr, Axetell, K., Jr, Guenther, C., Jutze, G. (1974). Development of Emission Factors for Fugitive Dust Sources. Document EPA-450/3-74-037, U.S. Environmental Protection Agency, Research Triangle Park, NC.

Fitz, D.R., Bumiller, K. (2000). Determination of $\mathrm{PM}_{10}$ emission rates from street sweepers. J. Air Waste Manage. Assoc. 50, 181-187. https://doi.org/10.1080/10473289.2000.10464004

Fitz, D.R. (2006). Particulate Matter Emissions Factors and Emission Inventory from Leaf Blowers in use in the San Joaquin Valley. Prepared for the San Joaquin Valley Unified Air Pollution Control District, Fresno, CA, January 27, 2006.

Fitz, D., Pankratz, D., Pederson, S., Bristow, J., Arcemont, G. (2006). Determination of Particulate 
Emission Rates from Leaf Blowers. Presented at the $15^{\text {th }}$ Annual Emission Inventory Conference, New Orleans, LA, May 16-18, 2006.

Hashmonay, R.A., Kagann, R.H., Rood, M.J., Kim, B.J., Kemme, M.R., Gillies, J. (2009). An Advanced Test Method for Measuring Fugitive Dust Emissions Using a Hybrid System of Optical Remote Sensing and Point Monitor Techniques, in: Kim, Y.J., Platt, U., Gu, M.B., Iwahashi, H. (Eds.), Atmospheric and Biological Environmental Monitoring, Springer Netherlands, Dordrecht, pp. 73-81. https://doi.org/10.1007/978-1-4020-9674-7_6

Holman, B.A., James, T.A., Ashbaugh, L.L., Flocchini, R.G. (2001). Lidar-assisted measurement of $\mathrm{PM}_{10}$ emissions from agricultural tilling in California's San Joaquin Valley - Part I: Lidar. Atmos. Environ. 35, 3251-3264. https://doi.org/10.1016/S1352-2310(00)00518-5

Laden, F., Schwartz, J., Speizer, F.E., Dockery, D.W. (2006). Reduction in fine particulate air pollution and mortality: Extended follow-up of the Harvard Six Cities study. Am. J. Respir. Crit. Care Med. 173, 667-672. https://doi.org/10.1164/rccm.200503-443oc

Lundgren, D.A. (1986). A measurement technique to quantify fugitive dust emissions from handling of granular products. J. Aerosol Sci. 17, 632-634. https://doi.org/10.1016/00218502(86)90176-X

Pope, C.A., Thun, M.J. Namboodiri, M.M., Dockery, D.W., Evans, J.S., Speizer, F.E., Heath, C.W. (1995). Particulate air pollution as a predictor of mortality in a prospective study of U.S. adults. Am. J. Respir. Crit. Care Med. 151, 669-674. https://doi.org/10.1164/ajrccm/151.3_Pt_1.669

Roney, J.A., White, B.R. (2006). Estimating fugitive dust emission rates using an environmental boundary layer wind tunnel. Atmos. Environ. 40, 7668-7685. https://doi.org/10.1016/j.atmos env.2006.08.015

U.S. Environmental Protection Agency (U.S. EPA) (1995). AP-42, Fifth Edition, Compilation of Air Pollutant Emission Factors, Volume 1: Stationary Point and Area Sources. U.S. Environmental Protection Agency. 